madhouses, family papers, Quarter Sessions records, etc., and anyone who already knows roughly what they are looking for should always start their enquiries in what appears to be the appropriate locality.

I cannot share Mr Guha's regrets that there is no "central archive' to act as a focus for research in the history of psychiatry, knowing this to be quite impossible from the very nature of archives. The particular records relating to George III to which he refers, for example, are in Lambeth Palace Library because the Archbishop of Canterbury headed the 'Queen's Council' which was appointed to take care of the King's person during his illness, and they are therefore part of the archives of the Archbishops of Canterbury. They might just as validly be carted off to a 'central archive' for the study of the work of Royal Consorts, as to a centre for the study of psychiatric history: as it is, one does at least know where to look for them. And anyone who has read Hunter and Macalpine on the subject will know that material relating to the King's illness is to be found scattered around, quite properly, in innumerable places, as is the case with the sources for virtually any historical subject. There is much essential information about Bethlem's early history in the City of London Records, and some in the Public Record Office, for example.

All that can be hoped for is the centralization of information about where such material is to be found, which is made increasingly possible by the advent of computers, but is, alas, still some way off for this particular branch of historical research. Meanwhile, it is an unfortunate truism that the more you know about the subject you are researching, the more likely you are to know where to find the material. The situation has not changed much since John Selden wrote in the seventeenth century: 'Out of their own nature it is known to men that are acquainted with Records where they are'.

The Archives

Bethlem Royal and Maudsley Hospitals

Beckenham, Kent

\section{DeAR SIRS}

I was very interested to read Dr Henry R. Rollin's appeal to preserve psychiatric memorabilia (Bulletin, February $1984,8,36)$. I am sure he is absolutely right that there is a grave danger that important and irreplaceable items may be destroyed in the process of closures. The experience at Warwick has been that the County Record Office has, indeed, been very glad to take documents of historical importance, including clinical records, and has taken great trouble in cataloguing and storing these. They are now available for scrutiny to bona fide interested persons, including researchers, but not others.

Apart from preservation, there is the danger that clinical records may find their way on to the open market and create problems with all that this implies with regard to confidentiality, particularly in areas where the population is still relatively static. Recently, in the catalogue of a medical antiquarian bookseller, clinical records from a psychiatric institution which had been closed down were advertised. I feel that there is a need for the College to approach the DHSS to see if an appropriate policy for important documents, particularly clinical records, can be formulated.

The Central Hospital

T. L. DuNN

Hatton, Warwick

\title{
Appeal for old medical journals
}

Dr Tamba Matturi of Bo in Sierra Leone appeals for back copies of psychiatric and general medical journals. He qualified at the Royal College of Surgeons in Dublin in 1969, and from 1973-78 did postgraduate training in psychiatry in the USA.

Dr Matturi is trying to establish a clinic in Bo (Sierra Leone's second city), and much of his practice is psychiatric. Like most developing countries, psychiatry is poorly funded in Sierra Leone, and the only mental hospital in the country (for 4 million people!) is bursting at the seams. Dr Matturi is using anti-psychotic drugs brought back from America in
1978 - they are nearly finished and there is no prospect of importing more. Members who have worked in developing countries will have first-hand experience of Dr Matturi's position. They will know the difficulties of good psychiatric practice and the isolation from other psychiatrists and current developments in the specialty.

Dr Matturi would appreciate old copies of the Journal (and other journals), but most of all, correspondence with psychiatrists in Britain who could encourage and support. Please write to: Dr Tamba Matturi, The Bo Clinic, PO Box 43, Bo, Sierra Leone, West Africa.

\section{Royal Patron}

May we draw readers' attention to the Registrar's report of the Winter Quarterly Meeting 1984 (Bulletin, April 1984, 8, 77) which announced that His Royal Highness the Prince of Wales has agreed to become Patron of the Royal College of Psychiatrists. 